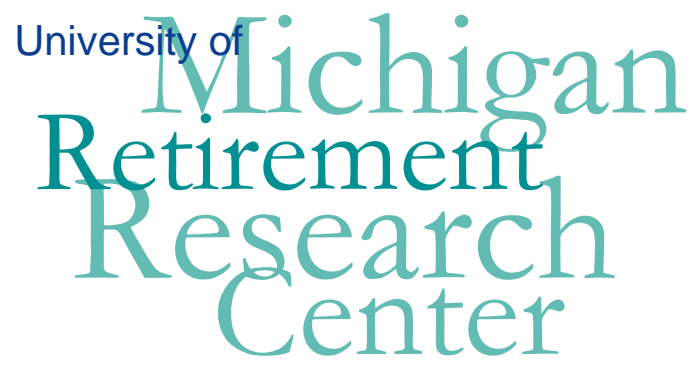

Working Paper

WP 2007-164

\begin{abstract}
Future Beneficiary Expectations of the Returns to Delayed Social Security Benefit Claiming and Choice Behavior

Jeff Dominitz, Angela Hung and Arthur van Soest
\end{abstract}

\begin{tabular}{|l|l|c|}
\hline $\mathrm{M}$ & $\mathrm{R}$ & Project \#: UM07-01 \\
\cline { 1 - 2 } $\mathrm{R}$ & $\mathrm{C}$ & http://ssrn.com/abstract $=1082827$ \\
\hline
\end{tabular} 


\title{
Future Beneficiary Expectations of the Returns to Delayed Social Security Benefit Claiming and Choice Behavior
}

\author{
Jeff Dominitz \\ RAND \\ Angela Hung \\ RAND \\ Arthur van Soest \\ Tilburg University and RAND
}

October 2007

\author{
Michigan Retirement Research Center \\ University of Michigan \\ P.O. Box 1248 \\ Ann Arbor, MI 48104 \\ http://www.mrrc.isr.umich.edu/
}

(734) 615-0422

\section{Acknowledgements}

This work was supported by a grant from the Social Security Administration through the Michigan Retirement Research Center (Grant \# 10-P-98362-5-04). The findings and conclusions expressed are solely those of the author and do not represent the views of the Social Security Administration, any agency of the Federal government, or the Michigan Retirement Research Center.

\section{Regents of the University of Michigan}

Julia Donovan Darrow, Ann Arbor; Laurence B. Deitch, Bingham Farms; Olivia P. Maynard, Goodrich; Rebecca McGowan, Ann Arbor; Andrea Fischer Newman, Ann Arbor; Andrew C. Richner, Grosse Pointe Park; S. Martin Taylor, Gross Pointe Farms; Katherine E. White, Ann Arbor; Mary Sue Coleman, ex officio 


\title{
Future Beneficiary Expectations of the Returns to Delayed Social Security Benefit Claiming and Choice Behavior
}

\author{
Jeff Dominitz, Angela Hung and Arthur van Soest
}

\begin{abstract}
We report on our preliminary findings from an innovative module of survey questions in the RAND American Life Panel designed to measure willingness to delay take-up of Social Security benefits. Among respondents who expect to stop working full time prior to turning age 62, over 60 percent report that they expect to start claiming Social Security benefits after they turn 63-that is, they expect to delay claiming. In contrast, among those who expect to stop full-time work sometime from age 62 to age 70, only about onequarter expect to delay claiming beyond the retirement age. Another main finding arises from reported probabilities of delayed claiming in hypothetical choice scenarios. These probabilities tend to be quite high relative to previous findings on delayed claiming outcomes. This result is particularly striking for those who are presented with information about the so-called "break-even age" for delayed claiming rather than information about the total amount of benefits that must be foregone during the one year delay.
\end{abstract}

\section{Authors' Acknowledgements}

We have received helpful comments from Arie Kapteyn and John Phillips and from participants in the 9th Annual Joint Conference of the Retirement Research Consortium and a seminar at Tilburg University

The research reported herein was pursuant to a grant from the U.S. Social Security Administration (SSA) funded as part of the Retirement Research Consortium (RRC) via the Michigan Retirement Research Center (MRRC), as well as grants from the National Institute on Aging (NIA). The findings and conclusions expressed are solely those of the authors and do not represent the views of SSA, the NIA, any agency of the Federal Government, the RRC, the MRRC, or the RAND Corporation. 
Annuitization of wealth confers many potential benefits to older Americans. According to data from the Health and Retirement Study (HRS) and other sources, however, the rate of voluntary annuitization is quite low in the United States. Of particular concern to policymakers is the risk of low levels of household income and wealth and, hence, consumption at advanced ages. This issue is being confronted in many other countries as well, where policies are in place or under consideration to mandate at least partial annuitization of defined contribution pensions (Brown, 2001; Lunnon, 2002).

The choice of initial claiming age for Social Security retirement benefits is analogous to the decision to purchase annuities (Coile et al., 2002). Currently, someone who stops working at age 62 has the option of either taking up Social Security benefits immediately or delaying claiming. If the retiree claims immediately, the monthly benefit is $75 \%$ of the "primary insurance amount" (PIA) calculated by the Social Security Administration (SSA). If the retiree instead delays claiming for one year, the monthly Social Security benefit will be $80 \%$ of the PIA. Thus, this one-year delay currently involves the implicit purchase of almost seven percent (.80/.75) more in Social Security annuities by the expenditure of one year of Social Security benefits. Under existing rules, the return to this one-year delay will gradually increase beginning in 2017 , to just over $7 \%(.75 / .70)$ in 2022 and beyond.

Prior to changes in the "early retirement reduction" that began in 2000, the return to the one-year delay from 62 to 63 exceeded 8\% (.867/.80), which Coile et al. (2002) found to be approximately actuarially fair for a single male based on population life tables and a real interest rate of $3 \%$. As such, these implicit annuity purchases are found to be attractively priced relative to private annuities (Brown and Warshawsky, 2000; Mitchell et al., 1999). The implicit annuity purchases should be particularly appealing to risk averse individuals who perceive relatively high probabilities of survival to advanced old age. ${ }^{1}$ Coile et al. (2002) use simulation evidence on optimal timing of benefit take-up to identify attributes of individuals who should find these annuities particularly appealing. For instance, they find that a married retiree garners greater

\footnotetext{
${ }^{1}$ Duggan and Soares (2002) review the legislative history of changes in the "normal retirement age" (NRA), "early retirement reduction", and "delayed retirement credit", and assess gender differences in actuarial equivalence of the reductions and credits. In an assessment of the early retirement reduction prior to changes based on 1983 amendments to the Social Security Act, they argue, "For benefit claims prior to the NRA, Congress originally intended that benefit adjustments would be actuarially equivalent on average". Duggan and Soares find an "actuarial premium for males, particularly low-earnings males, who accept benefits early and an actuarial loss for most females who accept benefits early". Thus, the implicit annuity purchases may only be attractively priced for some demographic groups.
} 
returns to delayed claiming than a single retiree, especially if the spouse is younger. The relationship between the optimal delay and household wealth is found to be either increasing or "U-shaped" and sensitive to the bequest motive. Of course, those with lower mortality risk and lower discount rates will find the annuities more attractive, all else equal.

Coile et al. find that the empirical pattern of variation in delayed claiming probabilities is generally consistent with predicted variation with these attributes, but the overall rate of delayed claiming is very low in their analysis of data from the New Beneficiary Data System. For example, among men who retired before reaching age 62 , less than $10 \%$ delayed claiming until age 63 or later. Hurd et al. (2004) calculate similar claiming rates based on HRS data and find that theoretical predictors of delayed claiming, including direct measures of subjective mortality risk, have little predictive value.

Even if the current Social Security program undergoes a major overhaul, policymakers still face important, if not more important, questions about how to encourage annuitization of wealth. President Bush's reform proposal called for personal retirement accounts that "would not be accessible prior to retirement" and would be "paid out over time" via "some combination of annuities to ensure a stream of monthly income over the worker's life expectancy, phased withdrawals indexed to life expectancy, and lump sum withdrawals."2 Lump sum withdrawals would not be permitted "if doing so would result in their moving below the poverty line." Thus, the question of when to initiate access to a personal retirement account and which payout options to choose would, for many low-income households, closely resemble the current decision to take up Social Security benefits.

What do current workers know about the returns to delayed claiming? To answer this question, one may start by looking to the personalized Social Security Statement sent annually to workers who are age 25 and older and not receiving Social Security benefits. For a worker born after 1960 who has earned enough credits to qualify for benefits, the Statement reports estimated retirement benefits at three different ages, as follows:

At your current earnings rate, if you stop working and start receiving benefits...

At age 62, your payment would be about $\$(0.70 \times$ PIA $)$ a month

If you continue working until...

\footnotetext{
${ }^{2}$ The reform proposal, dated February 2005 and entitled Strengthening Social Security in the $21^{\text {st }}$ Century, is available at http://www.whitehouse.gov/infocus/social-security/200501/socialsecurity.pdf. The cited text is taken from pages 7 and 8 .
} 
your full retirement age (67 years), your payment would be about...... $\$(1.00 \times$ PIA) a month

age 70 , your payment would be about.............................. $\$(1.24 \times$ PIA $)$ a month

We note two important elements of this information. First, the return to any one year deviation in claiming age is not presented. Second, for each conditional expectation, the claiming age is assumed to coincide with the age at which the individual stops working. Thus, the estimated change in benefits may arise in part from a change in the PIA rather than just a change in the reduction/credit multiplier that, for this worker, ranges from 0.70 to 1.24.

Current workers may look to the SSA website for additional estimates of their future retirement benefits. The website offers three "Benefit Calculators" 3 that vary in the extent of information required to be entered by the individual, ranging from the "Quick Calculator" that requires just the date of birth and current earnings to the "Online Calculator" that requires estimates of the entire earnings history to the "Detailed Calculator" application that must be downloaded.

Information describing the benefit rules is available throughout the website. In addition to detailed information on the reduction/credit multiplier rules, the page entitled "Early or Late Retirement" ${ }^{\prime 4}$ reports the percentage of the PIA associated with the desired retirement age entered by the individual. A page entitled "Break-Even Age" allows the individual to report estimated monthly benefits conditional on a self-selected "earlier retirement age" and "later retirement age." This page refers the reader to his or her Social Security Statement for benefit estimates. After retirement ages and benefit estimates are entered, the individual is informed:

Your estimated break-even age is XX.

If you expect to live beyond this age, it would be to your advantage to delay your retirement.

Note: interest is not considered in the calculation.

This language suggests that, as in the Statement, the benefit claiming age coincides with retirement age. ${ }^{6}$ We also note that this break-even age calculation ignores not only interest but also the insurance component of this annuity.

\footnotetext{
${ }^{3}$ Available at http://www.ssa.gov/planners/calculators.htm.

${ }_{5}^{4}$ Available at http://www.ssa.gov/OACT/quickcalc/early_late.html\#calculator.

${ }^{5}$ Available at http://www.ssa.gov/OACT/quickcalc/when2retire.html.

${ }^{6}$ This relationship holds tautologically if one defines "retirement" as the time of retirement benefit take-up, but we argue that workers are more likely to define retirement in terms of labor force participation behavior.
} 
In this paper, we present preliminary findings from our effort to dig deeper into what workers know about the returns to delayed claiming and how benefit rules impact retirement behavior. We designed a module of survey questions that elicits from future beneficiaries their expectations of retirement and claiming behavior and of the returns to delayed claiming. The module is being administered to members of American Life Panel (ALP), an ongoing panel study in which surveys are conducted via the Internet. We report here on data from 299 ALP members under age 60 who had completed the interview as of mid-September 2007, reported that they are not currently receiving Social Security benefits, and reported a positive probability of receiving benefits at some time in the future.

Our main findings arise from different pieces of evidence on expectations of delayed claiming and of the returns to delayed claiming. First, among respondents who expect to stop working full time prior to turning age 62, over 60 percent report that they expect to start claiming Social Security benefits after they turn 63 - that is, they expect to delay claiming. In contrast, among those who expect to stop full-time work sometime from age 62 to age 70, only about onequarter expect to delay claiming beyond the retirement age. Second, reported probabilities of delayed claiming in hypothetical choices scenarios tend to be quite high relative to previous findings on delayed claiming outcomes. This result is particularly striking for those who are presented with information about the break-even age rather than information about the total amount of benefits that must be foregone during the one year delay.

The high reported probabilities of delayed claiming may be attributed to our specification of benefit streams that exhibit returns that tend to be high relative to those that respondents expect to actually face at retirement. Many respondents expect little or no increase in benefits arising from delayed claiming and report that benefits will likely be cut substantially at some point after taking them up. In contrast, the scenarios specify that delayed claiming will increase benefits by more than 8 percent and these benefits will be guaranteed to keep up with inflation for the remainder of the individual's lifetime.

Alternatively, one may argue that the high reported probabilities of delayed claiming point to weaknesses inherent in any hypothetical choice experiment concerning a decision that may be many years ahead. If individuals actually believe they will be more patient than empirical evidence suggests they will—e.g., if choice behavior is consistent with hyperbolic discountingthen it important to gather evidence on the magnitude of the inconsistency between expectations 
and behaviors and on its impact on behavior over the life cycle. If it is the case that individuals planning for retirement expect to use the break-even age decision rule to choose claiming age but they ultimately base decisions on the importance of the immediate loss of one year of benefits, then the findings in this analysis will be helpful for predicting future deviations of expectations from behavior and the consequences thereof. For a recent example of the usefulness of stated preference data on a related decision - choices between defined benefit and defined contribution pensions - see van Rooij et al. (2007).

The paper is organized as follows. Section 1 describes key survey questions we have designed to measure expectations of the returns to delayed claiming and choice behavior. Section 2 describes the ALP data collected thus far. The empirical findings are presented in Section 3. Section 4 concludes.

\section{Measuring Expectations of Delayed Claiming Returns and Choices}

Unlike previous studies of the decision to delay receipt of Social Security benefits, our work is based on survey questions in which we directly elicit respondent willingness to delay via hypothetical choice questions under alternative scenarios of the returns to delayed claiming and descriptions thereof. We wish to do so in the context of a plausible retirement scenario, in terms of both future labor force participation and potential ages of benefit claiming. On the former, we ask the respondent to describe his or her retirement plans and then condition benefit claiming choices on these plans. Rather than choose a single reference age from which the respondent might delay-e.g., either 62 or the NRA—we elicit the respondent's expected age of claiming and then elicit the probability of delaying by one year conditional on the respondent's retirement plans and our description of the returns to claiming. To assess how our hypothetical scenario compares to respondent beliefs, we also elicit expectations of Social Security benefits. We describe key elements of the survey module below. The full text of the module is included in Appendix A.

Eliciting Information on Which to Condition Hypothetical Choices 
To begin the survey module, respondents are asked to report their labor force participation plans as follows:

We are interested in your plans for work and retirement when you are in your 60's and beyond. Which of the following statements best describes your plans?

1. I will not be working full time at age 60 or later.

2. I will be working full time at age 60 or later, but I will completely stop working sometime after age 60 .

3. I will be working full time at age 60 or later, but I will stop working full time sometime after age 60 and will likely continue working part time.

4. I will work full time for as long as I can, throughout my 60's and beyond.

Respondents who report that they will stop working full time are asked for the age at which they expect to stop working full time. We refer to this age as the expected retirement age $t_{R}{ }^{*}$.

The Social Security expectations questions begin with one that elicits the percent chance of receiving benefits in the future. Only those who report a positive chance are asked the subsequent questions. We allow that respondents may expect to retire and begin claiming Social Security benefits at different ages - e.g., they may expect to delay claiming. We therefore ask them to report the age at which they expect to begin claiming Social Security benefits. This age is labeled $t_{C}{ }^{*}{ }^{7}$ We then ask respondents to report expected Social Security benefits at age $t_{C}{ }^{*}$, conditional on retirement plans, including expected retirement age, as follows:

Suppose you [never work full time/ stop working full time at age $t_{R}{ }^{*} /$ work full time for as long as you can, throughout your 60's and beyond,] and start collecting Social Security benefits at age $t_{C}{ }^{*}$, about how much would you expect the payments to be in today's dollars.

The selection among the bracketed texts, separated by “/”, is determined by preceding responses. $^{8}$

\section{Measuring willingness to delay claiming}

To assess willingness to delay claiming, we construct hypothetical choice scenarios based on preceding responses and elicit probabilistic choice expectations for various values of the

\footnotetext{
${ }^{7}$ This question and all subsequent questions in this module are skipped if the respondent does not report a positive probability of receiving Social Security benefits at some time in the future.

${ }^{8}$ Here and below, the choice among the alternative texts given in brackets is determined by preceding responses. Underlined phrases are linked to a definition screen.
} 
return to delayed claiming. In particular, prior to being asked the central question of interestthat is, "What do you think is the percent chance that you would choose to wait one year to start collecting benefits at age $t_{C}{ }^{*}+1$ ?" - respondents are presented with the following scenario: Suppose you [never work full time/ stop working full time at age $t_{R} * /$ work full time for as long as you can, throughout your 60's and beyond], and you have not yet begun to collect Social Security benefits as you are about to turn age $t_{C}{ }^{*}$.

Suppose you must choose between starting to collect your benefits when you turn age $t_{C}{ }^{*}$ or when you turn age $t_{C}^{*+1}$.

If you choose to start to collect benefits at age $t_{C}^{*}$, then you will receive $\$ b$ per month, and this amount will be guaranteed to increase annually based on a "cost-of-living adjustment" in order to keep up with inflation for the remainder of your lifetime.

If instead you choose to wait one year to start collecting benefits at age $t_{C} *+1$, then you will be guaranteed to receive an additional $\$ \boldsymbol{r}_{1} \boldsymbol{b}$ each month [- that is, an extra $\$ r_{1} b \times 12$ each year-] in today's dollars. This amount will be increased annually based on a "costof-living adjustment" in order to keep up with inflation for the remainder of your lifetime.

We must choose a hypothetical monthly benefit $b$ at age $t_{C}{ }^{*}$. We choose $b$ equal to 1200,1800 or 2400 , with the specific value depending on the respondent's answer to the previous question eliciting expected monthly benefits at age $t_{C} *{ }^{9}$ The return to delayed take-up of Social Security benefits in the first choice scenario $r_{l}$ equals $1 / 12$. This value was chosen to approximate the reduction/credit multipliers in current benefit rules while yielding a reasonably rounded dollar value- $\$ 100, \$ 150$, or $\$ 200$. Respondents report up to four choice probabilities for increasing values of the return $r=1 / 12,1 / 8,1 / 6$, and $5 / 24$, respectively.

After describing this scenario, but still before eliciting the chance of delayed claiming, we present respondents with one of four information treatments, randomly assigned with equal probability. In the first treatment, respondents receive the same information about break-even age for delaying receipt of benefits that the SSA currently provides online:

\footnotetext{
${ }^{9}$ The thresholds for the question-branching algorithm are $\$ 1500$ and $\$ 2100$. Those with higher expected benefits are given higher hypothetical values $b$.
} 
If you expect to live beyond age $t_{C}{ }^{*}+(1 / r)$, then it would be to your advantage to delay your retirement (Note: interest is not included in this calculation). ${ }^{10}$

In contrast, the second treatment explicitly informs respondents of the amount of money they would forgo by delaying claiming and the number of years it would take to make up that amount in nominal terms.

By choosing to wait, you would give up one year of benefits (that is, $b \times 12$ dollars) while you are age $t_{C}{ }^{*}$, but you would make up that amount in $1 / r$ years.

The last two information treatments replicate the first two treatments, but for the addition of text that calls attention to the insurance component of an annuity. In particular, the third (fourth) treatment adds the following sentence to text of the first (second) treatment.

Moreover, you would continue to receive the extra $r b \times 12$ per year in the event that you live for many years after that.

\section{Measuring Social Security Benefit Expectations}

To assess the relative attractiveness of the hypothetical returns to delayed claiming, we must know something about the respondent's expected returns. We focus on three key components of these expectations: the increase in benefits at the claiming age, changes in real benefits after initial receipt, and the work record on which benefits will be based.

A point expectation of expected benefits at age $t_{C} *$ is elicited as described above. Similar text is used to elicit expected benefits conditional on delayed claiming until age $t_{C}{ }^{*+1}$. The difference between these two point expectations provides a convenient summary statistic for the expected returns to delayed claiming. However, expectations of real benefit reductions subsequent to take-up may reduce the perceived attractiveness of delayed claiming. We assess these beliefs by asking the following two questions:

Suppose you were to start collecting Social Security benefits at about age $t_{C} *$ or $t_{C} *+1$, what do you think is the percent chance that your benefits would keep up with inflation for the remainder of your lifetime? That is, what do you think is the percent chance that your Social Security benefits would increase at least as fast as the cost of living for the reminder of your lifetime?

and

\footnotetext{
${ }^{10}$ Here and below, ages and years are rounded up when $r=5 / 24$.
} 
Suppose you were to start collecting Social Security benefits at about age $t_{C}{ }^{*+1}$ or $t_{C}{ }^{*+1}$, what do you think is the percent chance that your benefits would be cut substantially at some point after you start collecting them?

Respondents who report relatively high probabilities of real benefit reductions may find the hypothetical choice scenarios more attractive, given that all benefits are said to be "guaranteed to increase annually based on a 'cost-of-living adjustment' in order to keep up with inflation for the remainder of your lifetime".

Finally, we note that the actual returns to delayed claiming currently depend on marital status and the work record on which benefits are based. To clarify the situation facing each respondent, we ask whether benefits are expected to be received "based on your own work record only; from a current, previous, or late spouse's work record only; or from both".

\section{American Life Panel Data}

This survey instrument was included as a module in the RAND American Life Panel (ALP). The ALP is an Internet panel of over 1000 respondents age 18 and over, recruited from among individuals age 18 and older who respond to the monthly Survey of Consumers conducted by the University of Michigan's Survey Research Center. ${ }^{11}$ Respondents in the panel either use their own computer to $\log$ on to the Internet or use a Web TV, which allows them to access the Internet using their television and a telephone line. The Web TV technology allows respondents who did not have previous Internet access to participate in the panel.

For this survey module on Social Security claiming, we restrict the sample to respondents who are younger than 60 years of age, do not currently receive any income from Social Security payments, and perceive a positive probability of receiving Social Security benefits in the future. As of mid-September, we have 299 observations in the sample that satisfy these restrictions.

In addition to responses to the Social Security claiming module, we have additional data on the background characteristics, preferences, and expectations of respondents. The attribute data include age, gender, marital status, education, and current labor force status. Respondents

\footnotetext{
${ }^{11}$ Prior to December 2006, respondents were required to be at least 40 years of age at the time of the Michigan survey interview.
} 
who are currently employed or have been employed in the previous two years are asked whether they are included in an employer-sponsored retirement plan, and this plan is identified as either a defined benefit or defined contribution plan or a mixture of the two. An advantage of using the ALP is that much additional information on the respondents is available from earlier interviews other than the attribute data include in the release of data from the present interview. In this preliminary analysis, however, we restrict attention to data reported in the release from these interviews.

Early on in the questionnaire, well before the Social Security claiming module, we pose several questions eliciting expectations and stated preferences that should be related to the decision to delay claiming. In particular, respondents report survival probabilities in the same form as those contained in the HRS data studied by Hurd et al. (2004). Here, the expectations concern the probability of living to age 70 and the probability of living to age 80 . Lastly, we use two separate series of hypothetical choice questions to elicit time preferences. Respondents are first asked to choose between a payment of $\$ 100$ "today" and a payment of $\$(1+\rho) 100$ "one year from now". We increase $\rho$ from 0.00 to 0.25 until the respondent chooses the delayed payment, so that we may characterize respondents according to the lowest value of $\rho$ at which they will delay payment. We also ask a parallel series of question where the choice is between $\$ 100$ "10 years from now" or $\$(1+\rho) 100$ "11 years from now". According to standard theory, the choice of a consumer who discounts exponentially will be invariant to the specified time horizons, whereas a hyperbolic discounter will be more likely to delay in the latter series of questions for any give value of $\rho$ (Laibson, 1997). To the extent that responses vary across time horizons, it is of interest to determine which is more predictive of stated preferences for delayed claiming that could take place no sooner than three years hence for respondents under age 60.

The entries in Table 1 describe the 299 ALP respondents, who range in age from 18 to 59 , with mean 47.6 and median $50 .{ }^{12}$ The sample is clearly not representative of the US adult population. ${ }^{13}$ Most respondents are male (62\%), a large majority are currently employed (81\%), and half report having earned a bachelor's degree.

\footnotetext{
${ }^{12}$ The great majority (85\%) of the respondents fall in the range 40 to 59 as a result of the age- $40+$ sampling restriction in place through 2006 (see previous footnote) and the less-than-60 restriction in place for this module.

${ }^{13}$ This statement holds if one compares respondents age 40 and over to the US population over age 40. Post-survey adjustment weights will be available in a future release of the data.
} 
All respondents answered the time preference and survival probability questions. Over one-third of respondents (37\%) always preferred to receive $\$ 100$ today rather than delay for one year, whereas $31 \%$ of respondents did so when choosing between 10 and 11 years hence. Taken together, $19 \%$ of respondents require a higher payment to delay one year from today relative to one year from 10 years hence.

Respondents are pretty evenly divided among the four retirement plans, but for the plan to work full time until at least age 60 and then completely stop working, which garners just 14\%. Among those who report an age at which they expect to stop working full time, the median is 62 with a range from 30 to 75 .

The reported percent chance of receiving Social Security benefits in the future averages 70.6 percent, with a range from 1 to $100 .{ }^{14}$ More than two-thirds expect to receive these benefits based only on their own work records and just 2 percent expect to do so based only on a spouse's record. The reports of the expected age of claiming average 66 with a median of 65 and a range from 55 to 95 . All but 26 of the reported ages fall in the range from 62 to 70 that should contain all reports if respondents are fully informed about current rules and fully anticipate that the rules will not change. ${ }^{15}$ Expected monthly benefits at the expected claiming age $t_{C} *$ average $\$ 1263$ with a median of $\$ 1200$ and a range from $\$ 50$ to $\$ 4238$. Expectations for claiming one year later at $t_{C}{ }^{*+1}$ average $\$ 1342$ with a median of $\$ 1200$ and a range from $\$ 50$ to $\$ 4500$. Most respondents report a low percent chance that benefits will keep up with inflation after take-up (median=25, mean=29.8) and most perceive at least a 50-50 chance that benefits will actually be cut substantially (median=50, mean=44.8).

The reported beliefs on future benefits indicate that, for many respondents, the delayed claiming scenarios we pose are very attractive relative to expected Social Security benefits and the expected returns to delayed claiming. For instance, the median expected benefit level conditional on claming at age $t_{C} *+1, \$ 1200$, falls short of the lowest value posed in the scenarios, $\$ 1300 .{ }^{16}$ Moreover, the benefits and returns to delayed claiming posed in the scenarios are "guaranteed" and " keep up with inflation for the remainder of your lifetime". It is perhaps not surprising then that the perceived probabilities of delayed claiming are high relative to

\footnotetext{
${ }^{14}$ In addition, twelve respondents reported a 0 percent chance and were therefore excluded from this sample.

${ }^{15}$ It is also important that respondents do not consider such benefits as disability or survivor benefits for which eligibility may precede age 62 .

${ }^{16}$ The median at $t_{C} *, \$ 1200$, equals the lowest values in the scenarios.
} 
observed outcomes in historical data. As reported in Table 1, the mean reported chance of delaying claiming in the first scenario, with an $8.33 \%$ increase in monthly benefits-e.g., $\$ 1300$ versus $\$ 1200$ - is a 57.9 percent chance, with a median of 60 , a standard deviation of 32.7 and a range from 0 to 100 . The mean increases to 69.1 with a $12.5 \%$ increase in benefits, 75.4 with a $16.67 \%$ increase, and 79.3 with a $20.83 \%$ increase. In each case the percent chance ranges from 0 to 100 , indicating that some respondents are unwilling to delay claiming even for very high returns. Most respondents, however, report a very high chance of delayed claiming in the most generous scenario, as demonstrated by the median of a 90 percent chance.

Table 2 describes the delayed claiming expectations for important subsets of respondents. The variation across information treatments is quite striking. Consider the first scenario. Among respondents given treatment 1 - "If you expect to live beyond age $t_{C}{ }^{*+12}$, then it would be to your advantage to delay your retirement" - the mean percent chance is 72.1 , whereas the mean is just 41.9 among respondents given treatment 2- "By choosing to wait, you would give up one year of benefits (that is, $b \times 12$ dollars) while you are age $t_{C}^{*}$, but you would make up that amount in 12 years". Thus, calling attention to the immediate benefits foregone seems to lead to reports of delayed claiming probabilities that are much closer to what has been previously observed. Qualitatively similar differences persist for the subsequent scenarios with higher returns to delayed claiming, as well as when treatment 3 respondents are pooled together with treatment 1 and treatment 4 respondents are pooled with treatment 2 . The additional information presented in treatments 3 and 4-"Moreover, you would continue to receive the extra $(1 / r) b \times 12$ per year in the event that you live for many years after that" - is associated with lower expectations of delayed claiming in one case (3 versus 1$)$ and higher expectations in the other (4 versus 2).

The entries in Table 2 also describe reports given by the sample of respondents who expect not to work full time after age 62 and expect to receive Social Security benefits based on their own records only. This group of ALP respondents more closely resembles, on expectation (loosely defined), a population that has been of interest in previous analyses because the behavioral predictions are clearer for them than for the broader population of all potential beneficiaries. Our small existing sample of 70 respondents gives reports that vary similarly across treatments but tend to be lower in each case relative to reports given by the 228 other 
respondents to at least of the hypothetical choice questions. We use the broader sample of respondents in the remainder of our analysis.

\section{Expectations of Delayed Claiming Returns and Choices}

Our survey module contains two main pieces of evidence on expectations of delayed claiming. Respondents report the expected age of stopping full-time work $t_{R}{ }^{*}$, if applicable, and then they report the expected age of take-up of benefits $t_{C}{ }^{*}$. If $t_{C} *$ is greater than the maximum of $t_{R} *$ and 62 , then we say that the respondent "expects to delay claiming". The second piece of evidence comes from the reported probability of choosing to claim at $t_{C} *+1$ rather than at $t_{C} *$.

Table 3 presents findings from the former piece of evidence. Among the 202 respondents who report that they plan to stop working full-time before they turn 71,82 expect to do so before age 62, 32 expect to do so at age 62,44 expect to do so at age 65, and the remaining 44 report values for $t_{R}^{*}$ in the interval from 63 to 70 other than 65. Among those with $t_{R}^{*}$ less than 62, only $34 \%$ report $t_{C}{ }^{*}=62$, whereas $61 \%$ expect to delay claiming beyond $62 .{ }^{17}$ In contrast, among those for whom $t_{R} *$ takes a value from 62 to $70,72 \%$ report $t_{C} *=t_{R} *$ and only $26 \%$ expect to delay claiming. The latter percentages are much closer to what has been observed in the past. However, it may very well be that early retirees will be more likely to delaying claiming in the future than has been previously observed. ${ }^{18}$ After all, benefits claimed at age 62 will be a markedly lower fraction of PIA than in the past - a value in the interval [.70,.75] as opposed to .80. The wealth holdings and demographic composition of early retirees will likely be rather different than previously observed, for this reason among others.

The evidence presented on choice probabilities in Table 2 is indicative of respondents who tend to be willing to delay claiming beyond the currently expected age $t_{C}{ }^{*}$. Reconciling these findings with the Table 3 evidence on expected retirement and claiming ages requires that

\footnotetext{
${ }^{17}$ In addition, 1 respondent reports an expected claiming age of 55 and 3 report an expected claiming age of 60.

${ }^{18}$ It should be noted that respondents may expect the initial age of eligibility to exceed 62 and, therefore, a reported claiming age of $t_{C}^{*}>62$ may not actually indicate an expectation of delay.
} 
we understand how the returns to delayed claiming posed in the hypothetical choice scenarios compare to what respondents expect them to be when the actual choice will be faced. ${ }^{19}$

One important dimension of the returns to delayed claiming is the expected change in monthly benefits arising from the delay. Figure 1 presents a scatter plot of the reported monthly benefit based on claiming at $t_{C}{ }^{*}$ and the difference in expected monthly benefits based on claiming in $t_{C}{ }^{*+1}$ as opposed to $t_{C} *$. A sizeable fraction (34\%) reports no difference in benefits based on a one year delay, while $61.4 \%$ report a higher benefit for delayed claiming. The nominal difference tends to increase with expected benefits at $t_{C} *$ Overall, the mean difference is $\$ 75.40$ and the median is $\$ 50$. When expressed as a percentage of expected benefits at $t_{C}^{*}$, the mean difference is $6.45 \%$ and the median is $3.85 \%$ The difference posed in the hypothetical scenarios ranges from $8.33 \%$ — $\$ 100, \$ 150$, or $\$ 200$ - in the first scenario to $20.83 \%$ in the final scenario.

We conclude the analysis with estimation of best linear predictors (BLPs) of delayed claiming. The first column of Table 4 presents least squares estimates of the BLP of the percent chance of delayed claiming in the first hypothetical choice scenario, where benefits are increased by $8.33 \%$ for a one-year delay.

First, consider some predictor variables that are directly related to a respondent's beliefs about the returns to delayed claiming of Social Security benefits: the expected change in initial benefits if claiming is delayed for one year, the belief that benefits will keep up with inflation after take-up, and the belief that benefits will be cut substantially after take-up. The hypothetical choice scenarios elicit the chance of delaying one year past the age when the respondent expects to actually claim benefits $t_{C}{ }^{*}$. Therefore, we expect that more positive assessments of actual future returns will be negatively related to the chance of delayed claiming in the hypothetical scenarios. To understand this prediction, consider a respondent for whom the expected return is worse than the hypothetical return as compared to a respondent for whom the expected return is better. The former respondent should be more likely to hypothetically delay claiming past $t_{C}{ }^{*}$ than should the latter respondent, all else equal.

We expect the coefficient on the percent chance that benefits will be cut substantially to be positive, because the posed scenario is better than what the respondent expects. We estimate a

\footnotetext{
${ }^{19}$ It is also important to note that the claiming delay described in Table 3 refers to the deviation of $t_{C} *$ from $\max \left\{t_{R}{ }^{*}, 62\right\}$, whereas the hypothetical claiming delay refers to a deviation from $t_{C}{ }^{*}$.
} 
coefficient of 0.135 , with an estimated standard error of 0.077 . Following the same line of reasoning, we expect negative coefficients on the percent chance that benefits will keep up with inflation and on the expected change in benefits associated with a one-year delay. Instead, both coefficients are estimated to be negative, but they are imprecisely estimated.

The subjective survival probability is another expectations variable for which we have a clear theoretical prediction for its relationship to delayed claiming. Those with lower mortality risk, as measured here by higher subjective probability of living to age 80 , should be more likely to delay claiming. In fact, we find that the BLP of the percent chance of delay increases by 0.252 for every 1 percentage point increase in the chance of living to 80 .

Now consider the variables capturing future time preferences. We construct dummy variables based on the minimum return that the respondent requires in order to delay payment from 10 years to 11 years. The omitted category is those who require a minimum return of greater than $25 \%$ in order to delay payment-i.e., those who never choose to delay payment in the hypothetical choice questions we pose. The estimate coefficients are all positive, indicating that those who discount the future less than members of the omitted group are more likely to delay claiming. The point estimates, however, are not monotonically declining with minimum required payment.

Lastly, we note that the estimated BLP varies with the information treatment variables in the same way that was described in Table 2. Of course, treatment assignment was designed to be independent of the other predictor variables, so this finding is not at all surprising. Respondents are most willing to delay claiming in Treatment 1 (the omitted category) in response to the break-even age information.

The second column of Table 4 presents analogous estimates where the outcome variable is instead an indicator for delayed claiming determined by whether the expected claiming age exceeds both the expected retirement age and what is now the earliest claiming age, 62. We restrict the sample to those 185 respondents who report an expected retirement age of less than 70 , currently the highest claiming age with an actuarial adjustment, and who report values for all of the predictor variables. For sake of comparison, the best linear predictor of the chance of delayed claiming in the first scenario is also estimated using this restricted sample, with results reported in the third column. 
Consider again the predictor variables describing the expected returned to delayed claiming. Unlike the previous case, we expect that higher expected returns from a one year delay will be positively associated with this delayed claiming indicator. After all, it should be these expected returns or, more precisely, the expected returns to the preceding one year delay, that induce responses to expect to delay in the first place. In contrast, those who expect to immediately claim benefits upon retirement may be doing so precisely because they expect low returns. The estimated coefficient, while relatively small and imprecisely estimated, supports this argument.

In stark contrast to the comparable finding from the hypothetical choice response, the estimated coefficient on survival probability is unsupportive of the basic prediction on mortality risk and delayed claiming. The estimated coefficients on the time preference indicators, however, are relatively precisely estimated, are of the predicted sign, and are monotonically decreasing as predicted. Finally, as one would hope given the experimental design, the coefficients on the information treatment indicators are much less precisely estimated than in the BLPs of the hypothetical choices.

\section{Conclusions}

We report on our findings from an innovative module of survey questions designed to measure willingness to delay take-up of Social Security benefits. We find that, among respondents who expect to stop working full time prior to turning age 62, over 60 percent report that they expect to start claiming Social Security benefits after they turn 63 - that is, they expect to delay claiming. In contrast, among those who expect to stop full-time work sometime from age 62 to age 70, only about one-quarter expect to delay claiming beyond the retirement age. Another main component of the analysis focuses on reported probabilities of delayed claiming in hypothetical choices scenarios. These probabilities tend to be quite high relative to previous findings on delayed claiming outcomes. This result is particularly striking for those who are presented with information about the break-even age for delayed claiming rather than information about the total amount of benefits that must be foregone during the one year delay. 
Our findings are still preliminary. The data collection for this survey module is ongoing. The increase in sample size will allow us to reach more definitive conclusions, especially with respect to the multivariate analysis. A larger sample size will also allow for estimation of structural models of the decision to delay claiming. Additionally, future work will utilize data from previous waves of the ALP that should be very helpful for this analysis, including data on household wealth and on measures of financial literacy based on responses to a questionnaire adapted from that analyzed by Lusardi and Mitchell (2005). We also intend to conduct a supplemental analysis using data from the HRS to study how reported expectations of claiming age correspond to actual claiming realizations reported in subsequent interviews.

\section{References}

Brown, Jeffrey R. 2001. "Private Pensions, Mortality Risk, and the Decision to Annuitize", Journal of Public Economics, Vol. 82, No. 1, October 2001, p. 29-62.

Brown, Jeffrey R., and Mark J. Warshawsky. 2000. "Longevity-Insured Retirement Distributions from Pension Plans: Market and Regulatory Issues", Brookings Conference on Public Policies and Private Pensions, Washington, DC, September 21-22.

Coile, Courtney, Peter Diamond, Jonathan Gruber, and Alain Jousten. 2002. "Delays in Claiming Social Security Benefits," Journal of Public Economics, 84:3, 357-385.

Duggan, James E., and Christopher J. Soares. 2002. "Actuarial Nonequivalence in Early and Delayed Social Security Benefit Claims,” Public Finance Review, May, 188-207.

Hurd, Michael D., James P. Smith, and Julie M. Zissimopoulos. 2004. "The Effects of Subjective Survival on Retirement and Social Security Claiming," Journal of Applied Econometrics, 19, 761-775.

Laibson, David. 1997. "Golden Eggs and Hyperbolic Discounting”, Quarterly Journal of Economics, 112(2), 443-477.

Lunnon, Martin. 2002. “Annuitization: Major Issues”, Seminar for Social Security Actuaries and Statisticians: Actuarial Aspects of Pension Reform, International Social Security Administration, Moscow, July 3-5 2002.

Lusardi, Annamaria, and Olivia Mitchell (2005). "Financial Literacy and Planning: Implications for Retirement Wellbeing," MRRC working paper 2005-108, Michigan Retirement Research Center. 
Mitchell, Olivia, James Poterba, Mark Warshawsky, and Jeffrey Brown. 1999. "New Evidence on the Money's Worth of Individual Annuities," American Economic Review, 89:5, 1299-1318.

Van Rooij, Maarten C.J., Clemens J.M. Kool, and Henriette M. Prast. 2007. "Risk-Return Preferences in the Pension Domain: Are People Able to Choose?" Journal of Public Economics, 91(3-4), 2001-2027. 


\section{Appendix A - American Life Panel Survey Questions}

1. We are interested in your plans for work and retirement when you are in your 60's and beyond. Which of the following statements best describes your plans?

1. I will not be working full time at age 60 or later.

2. I will be working full time at age 60 or later, but I will completely stop working sometime after age 60 .

3. I will be working full time at age 60 or later, but I will stop working full time sometime after age 60 and will likely continue working part time.

4. I will work full time for as long as I can, throughout my 60's and beyond.

If respondent chooses (2) or (3)

1a. At what age do you expect to stop working full time? AGE (refer to this age as $t_{R}{ }^{*}$ )

If respondent chooses (1), then

1b. You indicated that you do not plan to be working full time at age 60 or later. At what age do you expect to stop working full time?

or AGE (refer to this age as $t_{R}{ }^{*}$ )

I do not expect to ever work full time.

2. Do you currently receive any income from Social Security?

Yes

No

If respondent answers "yes," then skip the remainder of the section

3. Using any number from one to five, where one equals totally inadequate and five equals very satisfactory, how would you rate the retirement income you expect to receive from Social security and any job-related retirement plans, such as $\underline{401(\mathrm{k}) \text { plans }}$ and all other types of pensions?

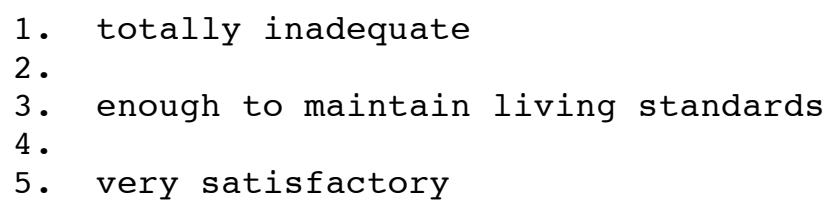

4. What do you think is the percent chance (what are the chances out of 100) that you will receive Social Security benefits at some time in the future?

\section{If respondent answers "0 percent," then skip the remainder of the section}

5. If you were to receive Social Security benefits at some time in the future, do you expect to get them based on your own work record only; from a 
current, previous or late spouse's work record only; or from both?

1. Your own record only

5. Spouse's record only

3. Both records

The fills in questions $6-8$ depend on response to question 1:

6. [Suppose you never work full time. / Suppose you stop working full time at age $t_{R}{ }^{*}$. / Suppose you work full time for as long as you can, throughout your 60 's and beyond.] At what age would you expect to start collecting these Social Security benefits? (30-96) AGE (refer to this age as $\boldsymbol{t}_{c}{ }^{*}$ )

7. Suppose you [never work full time and/ stop working full time at age $\boldsymbol{t}_{\boldsymbol{R}}$ * and/ work full time for as long as you can, throughout your 60's and beyond, and start collecting Social security benefits at age $t_{c}{ }^{*}$. About how much would you expect the monthly payments to be in today's dollars? $\$$ per month

8. Suppose as before, [that you never work full time, but / that you stop working full time at age $t_{R}{ }^{*}$, but/ that you work full time for as long as you can, throughout your 60's and beyond, but] you were to wait to start collecting Social security benefits until age $\boldsymbol{t}_{c}{ }^{*}+1$. About how much would you expect the monthly payments to be in today's dollars? $\$$ (amount) per month

9. Suppose you were to start collecting Social security benefits at about age $\boldsymbol{t}_{c}$ * or $\boldsymbol{t}_{c}{ }^{*+1}$, what do you think is the percent chance that your benefits would keep up with inflation for the remainder of your lifetime? That is, what do you think is the percent chance that your social security benefits would increase at least as fast as the cost of living for the reminder of your lifetime?

10. Suppose you were to start collecting Social security benefits at about age $\boldsymbol{t}_{c}{ }^{*}$ or $\boldsymbol{t}_{c}{ }^{*+1}$, what do you think is the percent chance that your benefits would be cut substantially at some point after you start collecting them?

Hypothetical Choice Social security Questions

Phrase fills determined by response to question 1.

Dollar amount, $b$, determined by response to question 9 If questiong $<1500$, then $b=1200$

If $1500<=$ questiong $<2100$, then $b=1800$

If questiong $>=2100$, then $b=2400$

Next we have a series of questions in which we describe an important decision that you may face in the future. Please read the instructions carefully so that the choices are clear to you and answer the questions as best you can.

Hla. Suppose you [never work full time/ stop working full time at age $t_{R} * /$ work full time for as long as you can, throughout your 60's and beyond], and you have not yet begun to collect social security benefits as you are about 
to turn age $t_{C}{ }^{*}$

Suppose you must choose between starting to collect your benefits when you turn age $t_{c}{ }^{*}$ or when you turn age $t_{c}{ }^{*}+1$.

If you choose to start to collect benefits at age $t_{c}$, then you will receive $\$ b$ per month, and this amount will be guaranteed to increase annually based on a "cost-of-living adjustment" in order to keep up with inflation for the remainder of your lifetime.

If instead you choose to wait one year to start collecting benefits at age $t_{c} *+1$, then you will be guaranteed to receive an additional $\$(1 / 12) b$ each month [-that is, an extra $\$(1 / 12) b \times 12$ each year-] in today's dollars. This amount will be increased annually based on a "cost-of-living adjustment" in order to keep up with inflation for the remainder of your lifetime.

RANDONLY ASSIGNED VARIANTS IN THE PRESENTATION (each respondent gets same variant in all subsequent questions)

Treatment 1: If you expect to live beyond age $t_{c} *+12$, then it would be to your advantage to delay your retirement (Note: interest is not included in this calculation).

Treatment 2: By choosing to wait, you would give up one year of benefits (that is, $b \times 12$ dollars) while you are age $t_{c} *$, but you would make up that amount in 12 years.

Treatment 3: If you expect to live beyond age $t_{C} *+12$, then it would be to your advantage to delay your retirement (Note: interest is not included in this calculation). Moreover, you would continue to receive the extra $(1 / 12) b \times 12$ per year in the event that you live for many years after that.

Treatment 4: By choosing to wait, you would give up one year of benefits (that is, $b \times 12$ dollars) while you are age $t_{C} *$, but you would make up that amount in 12 years. Moreover, you would continue to receive the extra (1/12)b $\times 12$ per year in the event that you live for many years after that.

What do you think is the percent chance that you would choose to wait one year to start collecting benefits at age $t_{c} *+1$ ?

If percent chance $=100$, then skip the remainder of the section.

H1b. Suppose now that if you choose to wait one year to start collecting benefits at age $t_{c} *+1$, then you will be guaranteed to receive an additional $\$(1 / 8) b$ each month [-that is, an extra $\$(1 / 8) b \times 12$ each year-] in today's dollars. This amount will be increased annually based on a "cost-of-living adjustment" in order to keep up with inflation for the remainder of your lifetime.

Treatment 1: If you expect to live beyond age $t_{C} *+8$, then it would be to your advantage to delay your retirement (Note: interest is not included in this calculation).

Treatment 2: By choosing to wait, you would give up one year of benefits 
(that is, $b \times 12$ dollars) while you are age $t_{c}$, but you would make up that amount in 8 years.

Treatment 3: If you expect to live beyond age $t_{c} *+8$, then it would be to your advantage to delay your retirement (Note: interest is not included in this calculation). Moreover, you would continue to receive the extra $(1 / 8) b \times 12 \mathrm{per}$ year in the event that you live for many years after that.

Treatment 4: By choosing to wait, you would give up one year of benefits (that is, $b \times 12$ dollars) while you are age $t_{c}{ }^{*}$, but you would make up that amount in 8 years. Moreover, you would continue to receive the extra (1/8)b $\times 12$ per year in the event that you live for many years after that.

What do you think is the percent chance that you would choose to wait one year to start collecting benefits at age $t_{c} *+1$ ?

If percent chance $=100$, then skip the remainder of the section.

H1c. Suppose now that if you choose to wait one year to start collecting benefits at age $t_{C} *+1$, then you will be guaranteed to receive an additional $\$(1 / 6) b$ each month [-that is, an extra $\$(1 / 6) b \times 12$ each year-] in today's dollars. This amount will be increased annually based on a "cost-of-living adjustment" in order to keep up with inflation for the remainder of your lifetime.

Treatment 1: If you expect to live beyond age $t_{c} *+6$, then it would be to your advantage to delay your retirement (Note: interest is not included in this calculation).

Treatment 2: By choosing to wait, you would give up one year of benefits (that is, $b \times 12$ dollars) while you are age $t_{c}{ }^{*}$, but you would make up that amount in 6 years.

Treatment 3: If you expect to live beyond age $t_{C} *+6$, then it would be to your advantage to delay your retirement (Note: interest is not included in this calculation). Moreover, you would continue to receive the extra $(1 / 6) b \times 12$ per year in the event that you live for many years after that.

Treatment 4: By choosing to wait, you would give up one year of benefits (that is, $b \times 12$ dollars) while you are age $t_{c}{ }^{*}$, but you would make up that amount in 6 years. Moreover, you would continue to receive the extra (1/6)b $\times 12$ per year in the event that you live for many years after that.

What do you think is the percent chance that you would choose to wait one year to start collecting benefits at age $t_{C} *+1$ ?

If percent chance $=100$, then skip the remainder of the section.

H1d. Suppose now that if you choose to wait one year to start collecting benefits at age $t_{c} *+1$, then you will be guaranteed to receive an additional $\$(5 / 24) b$ each month [-that is, an extra $\$(5 / 24) b \times 12$ each year-] in today's dollars. This amount will be increased annually based on a "cost-of-living adjustment" in order to keep up with inflation for the remainder of your 
lifetime.

Treatment 1: If you expect to live beyond age $t_{C} *+5$, then it would be to your advantage to delay your retirement (Note: interest is not included in this calculation).

Treatment 2: By choosing to wait, you would give up one year of benefits (that is, $b \times 12$ dollars) while you are age $t_{C} *$, but you would make up that amount in 5 years.

Treatment 3: If you expect to live beyond age $t_{c} *+5$, then it would be to your advantage to delay your retirement (Note: interest is not included in this calculation). Moreover, you would continue to receive the extra (5/24)b $\times 12$ per year in the event that you live for many years after that.

Treatment 4: By choosing to wait, you would give up one year of benefits (that is, $b \times 12$ dollars) while you are age $t_{c}{ }^{*}$, but you would make up that amount in 5 years. Moreover, you would continue to receive the extra (5/24)b $\times 12$ per year in the event that you live for many years after that.

What do you think is the percent chance that you would choose to wait one year to start collecting benefits at age $t_{c} *+1$ ? 
Table 1: Descriptive Statistics

\begin{tabular}{|c|c|c|c|c|c|c|}
\hline Variable & $\mathrm{n}$ & mean & median & std dev & $\min$ & $\max$ \\
\hline Age (years) & 299 & 47.6 & 50 & 9.09 & 18 & 59 \\
\hline Gender $(=1$ if female $)$ & 299 & 0.38 & & & & \\
\hline Currently married or living with partner ( $=1$ if yes) & 299 & 0.69 & & & & \\
\hline Never married ( $=1$ if yes) & 299 & 0.16 & & & & \\
\hline \multicolumn{7}{|l|}{ Highest Educational Attainment } \\
\hline High School or Less (=1 if yes) & 299 & 0.16 & & & & \\
\hline Some College & 299 & 0.34 & & & & \\
\hline Bachelor's Degree or More & 299 & 0.50 & & & & \\
\hline Currently Employed (=1 if yes) & 299 & 0.81 & & & & \\
\hline DB pension on current job ( $=1$ if yes) & 299 & 0.28 & & & & \\
\hline DC pension on current job ( $=1$ if yes) & 299 & 0.44 & & & & \\
\hline Percent chance of living to age 70 & 299 & 79.91 & 85 & 18.66 & 20 & 100 \\
\hline Percent chance of living to age 80 & 299 & 66.76 & 70 & 23.72 & 5 & 100 \\
\hline \multicolumn{7}{|l|}{ Time Preference: Today vs. 1 Year From Now } \\
\hline$\$ 100$ (=1 if yes) & 299 & 0.03 & & & & \\
\hline$\$ 105$ & 299 & 0.08 & & & & \\
\hline$\$ 110$ & 299 & 0.20 & & & & \\
\hline$\$ 115$ & 299 & 0.11 & & & & \\
\hline$\$ 120$ & 299 & 0.12 & & & & \\
\hline$\$ 125$ & 299 & 0.08 & & & & \\
\hline does not delay & 299 & 0.37 & & & & \\
\hline \multicolumn{7}{|l|}{ Time Preference: 10 vs. 11 Years From Now } \\
\hline \multicolumn{7}{|l|}{ (dollar value at which delays payment) } \\
\hline$\$ 100$ (=1 if yes) & 299 & 0.03 & & & & \\
\hline$\$ 105$ & 299 & 0.09 & & & & \\
\hline$\$ 110$ & 299 & 0.18 & & & & \\
\hline$\$ 115$ & 299 & 0.11 & & & & \\
\hline$\$ 120$ & 299 & 0.19 & & & & \\
\hline$\$ 125$ & 299 & 0.09 & & & & \\
\hline does not delay & 299 & 0.31 & & & & \\
\hline \multicolumn{7}{|l|}{ Retirement Plans } \\
\hline no full-time work at 60 or later ( $=1$ if yes) & 299 & 0.26 & & & & \\
\hline completely stop working after 60 & 299 & 0.14 & & & & \\
\hline likely change to part-time after 60 & 299 & 0.28 & & & & \\
\hline full-time work "as long as I can" & 299 & 0.31 & & & & \\
\hline Expected retirement age (years) & 179 & 61.95 & 63 & 6.16 & 30 & 75 \\
\hline Percent chance ever receive Social Security benefits & 299 & 70.57 & 80 & 28.12 & 1 & 100 \\
\hline \multicolumn{7}{|l|}{ Source of Social Security Benefits } \\
\hline own record (=1 if yes) & 299 & 0.64 & & & & \\
\hline spouse's record & 299 & 0.03 & & & & \\
\hline both record & 299 & 0.33 & & & & \\
\hline Expected claiming age (years) & 298 & 66.3 & 65 & 3.76 & 55 & 95 \\
\hline Expected monthly benefits at claiming age (\$) & 295 & 1263 & 1200 & 726 & 50 & 4238 \\
\hline Expected monthly benefits if delay one year $(\$)$ & 290 & 1342 & 1200 & 786 & 0 & 4500 \\
\hline Percent chance benefits keep up with inflation & 296 & 29.8 & 25 & 26.29 & 0 & 100 \\
\hline Percent chance benefits cut substantially & 296 & 44.8 & 50 & 28.02 & 0 & 100 \\
\hline \multicolumn{7}{|l|}{ Delayed Claiming Scenarios } \\
\hline percent chance with return of $1 / 12$ & 298 & 57.9 & 60 & 32.70 & 0 & 100 \\
\hline percent chance with return of $1 / 8$ & 272 & 69.1 & 75 & 26.60 & 0 & 100 \\
\hline percent chance with return of $1 / 6$ & 271 & 75.4 & 80 & 24.57 & 0 & 100 \\
\hline percent chance with return of $5 / 24$ & 270 & 79.3 & 90 & 24.63 & 0 & 100 \\
\hline
\end{tabular}


Table 2: Percent Chance of Delayed Claiming

\begin{tabular}{|c|c|c|c|c|c|c|c|}
\hline \begin{tabular}{|c|} 
Delayed Claiming \\
Scenario
\end{tabular} & Sample & $\mathrm{n}$ & mean & median & std dev & $\min$ & $\max$ \\
\hline \multirow{10}{*}{$\begin{array}{c}\text { Percent Chance } \\
\text { With Return Of } \\
1 / 12\end{array}$} & Full Sample & 298 & 57.9 & 60 & 32.7 & 0 & 100 \\
\hline & Full -- Treatment 1 & 60 & 72.1 & 80 & 27.5 & 0 & 100 \\
\hline & Full -- Treatment 2 & 77 & 41.9 & 50 & 35.1 & 0 & 100 \\
\hline & Full -- Treatment 3 & 80 & 65.1 & 70 & 27.8 & 0 & 100 \\
\hline & Full -- Treatment 4 & 81 & 55.4 & 50 & 32.0 & 0 & 100 \\
\hline & Expect No Full-Time Work After 62, Benefits Based On Own Record & 70 & 47.9 & 50 & 34.9 & 0 & 100 \\
\hline & No Full-Time After 62, Own Record -- Treatment 1 & 9 & 63.8 & 65 & 41.1 & 0 & 100 \\
\hline & No Full-Time After 62, Own Record -- Treatment 2 & 18 & 30.3 & 10 & 36.2 & 0 & 100 \\
\hline & No Full-Time After 62, Own Record -- Treatment 3 & 15 & 53.9 & 50 & 29.2 & 10 & 99 \\
\hline & No Full-Time After 62, Own Record -- Treatment 4 & 28 & 49.5 & 50 & 32.0 & 0 & 100 \\
\hline \multirow{10}{*}{$\begin{array}{c}\text { Percent Chance } \\
\text { With Return Of } 1 / 8\end{array}$} & Full Sample & 272 & 69.1 & 75 & 26.6 & 0 & 100 \\
\hline & Full -- Treatment 1 & 57 & 79.9 & 80 & 19.7 & 10 & 100 \\
\hline & Full -- Treatment 2 & 64 & 55.8 & 55 & 30.1 & 0 & 100 \\
\hline & Full -- Treatment 3 & 78 & 70.9 & 75 & 24.6 & 2 & 100 \\
\hline & Full -- Treatment 4 & 73 & 70.3 & 75 & 25.7 & 5 & 100 \\
\hline & Expect No Full-Time Work After 62, Benefits Based On Own Record & 61 & 61.0 & 70 & 32.3 & 5 & 100 \\
\hline & No Full-Time After 62, Own Record -- Treatment 1 & 7 & 87.0 & 99 & 19.0 & 50 & 100 \\
\hline & No Full-Time After 62, Own Record -- Treatment 2 & 12 & 41.3 & 35 & 36.4 & 5 & 100 \\
\hline & No Full-Time After 62, Own Record -- Treatment 3 & 15 & 63.9 & 75 & 27.3 & 10 & 100 \\
\hline & No Full-Time After 62, Own Record -- Treatment 4 & 27 & 61.4 & 70 & 31.6 & 5 & 100 \\
\hline \multirow{10}{*}{$\begin{array}{c}\text { Percent Chance } \\
\text { With Return Of } 1 / 6\end{array}$} & Full Sample & 271 & 75.4 & 80 & 24.6 & 0 & 100 \\
\hline & Full -- Treatment 1 & 57 & 84.8 & 90 & 18.9 & 10 & 100 \\
\hline & Full -- Treatment 2 & 63 & 64.3 & 65 & 27.2 & 5 & 100 \\
\hline & Full -- Treatment 3 & 78 & 74.9 & 80 & 25.5 & 0 & 100 \\
\hline & Full -- Treatment 4 & 73 & 78.3 & 80 & 21.7 & 5 & 100 \\
\hline & Expect No Full-Time Work After 62, Benefits Based On Own Record & 61 & 69.5 & 75 & 29.7 & 5 & 100 \\
\hline & No Full-Time After 62, Own Record -- Treatment 1 & 7 & 85.7 & 100 & 21.5 & 50 & 100 \\
\hline & No Full-Time After 62, Own Record -- Treatment 2 & 12 & 47.5 & 50 & 33.7 & 5 & 100 \\
\hline & No Full-Time After 62, Own Record -- Treatment 3 & 15 & 70.6 & 75 & 28.8 & 10 & 100 \\
\hline & No Full-Time After 62, Own Record -- Treatment 4 & 27 & 74.6 & 80 & 26.0 & 5 & 100 \\
\hline \multirow{10}{*}{$\begin{array}{l}\text { Percent Chance } \\
\text { With Return Of } \\
5 / 24\end{array}$} & Full Sample & 270 & 79.3 & 90 & 24.6 & 0 & 100 \\
\hline & Full -- Treatment 1 & 57 & 86.9 & 99 & 21.5 & 10 & 100 \\
\hline & Full -- Treatment 2 & 63 & 70.5 & 75 & 26.4 & 1 & 100 \\
\hline & Full -- Treatment 3 & 77 & 75.5 & 90 & 25.8 & 0 & 100 \\
\hline & Full -- Treatment 4 & 73 & 81.9 & 90 & 21.9 & 5 & 100 \\
\hline & Expect No Full-Time Work After 62, Benefits Based On Own Record & 61 & 75.5 & 90 & 28.3 & 1 & 100 \\
\hline & No Full-Time After 62, Own Record -- Treatment 1 & 7 & 88.6 & 100 & 20.4 & 50 & 100 \\
\hline & No Full-Time After 62, Own Record -- Treatment 2 & 12 & 53.4 & 50 & 33.7 & 1 & 100 \\
\hline & No Full-Time After 62, Own Record -- Treatment 3 & 15 & 78.6 & 99 & 25.7 & 25 & 100 \\
\hline & No Full-Time After 62, Own Record -- Treatment 4 & 27 & 80.2 & 90 & 25.0 & 5 & 100 \\
\hline
\end{tabular}


Table 3: Retirement and Claiming Age Expectations

\begin{tabular}{|c|c|c|c|c|c|c|c|c|}
\hline \multirow{2}{*}{$\begin{array}{l}\text { Age At Which Respondent Expects to Have } \\
\text { Stopped Working Full Time }\left(t_{R}{ }^{*}\right)\end{array}$} & \multicolumn{8}{|c|}{ Age At Which Respondent Expects to Start Collecting Social Security Benefits $\left(t_{C}{ }^{*}\right)$} \\
\hline & $\mathrm{n}$ & mean & median & mode & $\min$ & $\max$ & $t_{C}^{*}=\max \left\{t_{R}^{*}, 62\right\}$ & $t_{C}{ }^{*}>\max \left\{t_{R}{ }^{*}, 62\right\}$ \\
\hline$<60$ & 69 & 34.5 & 65 & 62 & 55 & 72 & $36.2 \%$ & $59.4 \%$ \\
\hline 60 or 61 & 13 & 63.8 & 65 & 65 & 60 & 67 & $23.1 \%$ & $69.2 \%$ \\
\hline 62 & 32 & 63.0 & 62 & 62 & 62 & 69 & $71.9 \%$ & $28.1 \%$ \\
\hline 63 or 64 & 8 & 65.3 & 64 & 63,67 & 63 & 68 & $50.0 \%$ & $50.0 \%$ \\
\hline 65 & 44 & 66.0 & 65 & 65 & 65 & 70 & $63.6 \%$ & $36.4 \%$ \\
\hline 66 or 67 & 19 & 66.4 & 66 & 67 & 65 & 67 & $89.5 \%$ & $0.0 \%$ \\
\hline $68-70$ & 17 & 68.8 & 70 & 70 & 62 & 73 & $64.7 \%$ & $11.8 \%$ \\
\hline$>70$ or Never & 96 & 68.9 & 70 & 70 & 62 & 95 & $1.0 \%$ & $0.0 \%$ \\
\hline
\end{tabular}


Table 4: Best Linear Predictors of Delayed Claiming Expectations

\begin{tabular}{|c|c|c|c|}
\hline \multirow[b]{2}{*}{$\underline{\text { Predictor Variable }}$} & \multicolumn{3}{|c|}{ Outcome Variable } \\
\hline & $\begin{array}{c}\text { Percent Chance of } \\
\text { Delayed Claiming } \\
\text { with Return } \mathrm{r}_{1}=1 / 12\end{array}$ & $\begin{array}{c}\text { Delay Claiming } \\
\text { Expectations Indicator } \\
\underline{1\left[\mathrm{t}_{\mathrm{C}}{ }^{*}>\max \left(\mathrm{t}_{\underline{\underline{t}}}{ }^{*}, 62\right)\right]}\end{array}$ & $\begin{array}{c}\text { Percent Chance of } \\
\text { Delayed Claiming } \\
\text { with Return } r_{1}=1 / 12\end{array}$ \\
\hline Age & $\begin{array}{l}-0.167 \\
(0.240)\end{array}$ & $\begin{array}{l}-0.012 \\
(0.004)\end{array}$ & $\begin{array}{l}-0.230 \\
(0.301)\end{array}$ \\
\hline Currently Married & $\begin{array}{l}-2.775 \\
(4.358)\end{array}$ & $\begin{array}{c}0.006 \\
(0.091)\end{array}$ & $\begin{array}{l}-1.184 \\
(6.022)\end{array}$ \\
\hline Currently Employed & $\begin{array}{l}-5.482 \\
(6.137)\end{array}$ & $\begin{array}{l}-0.070 \\
(0.109)\end{array}$ & $\begin{array}{l}-9.443 \\
(7.366)\end{array}$ \\
\hline DB pension on current job & $\begin{array}{l}-1.379 \\
(4.073)\end{array}$ & $\begin{array}{l}-0.019 \\
(0.085)\end{array}$ & $\begin{array}{c}0.011 \\
(5.951)\end{array}$ \\
\hline DC pension on current job & $\begin{array}{l}-6.152 \\
(4.261)\end{array}$ & $\begin{array}{l}-0.130 \\
(0.088)\end{array}$ & $\begin{array}{l}-0.240 \\
(6.398)\end{array}$ \\
\hline Female & $\begin{array}{l}-2.553 \\
(4.339)\end{array}$ & $\begin{array}{l}-0.095 \\
(0.085)\end{array}$ & $\begin{array}{l}-8.708 \\
(5.987)\end{array}$ \\
\hline Some College & $\begin{array}{l}-3.818 \\
(2.852)\end{array}$ & $\begin{array}{c}0.025 \\
(0.118)\end{array}$ & $\begin{array}{c}0.285 \\
(7.783)\end{array}$ \\
\hline Bachelor's Degree or More & $\begin{array}{l}-2.852 \\
(2.682)\end{array}$ & $\begin{array}{c}0.027 \\
(0.125)\end{array}$ & $\begin{array}{l}-2.546 \\
(7.570)\end{array}$ \\
\hline Percent chance of living to age 80 & $\begin{array}{c}0.252 \\
(0.090)\end{array}$ & $\begin{array}{c}0.000 \\
(0.002)\end{array}$ & $\begin{array}{c}0.255 \\
(0.123)\end{array}$ \\
\hline $\begin{array}{c}\text { Requires at least } 0 \%-5 \% \text { return to delay payment to } 11 \\
\text { years from now }\end{array}$ & $\begin{array}{l}9.412 \\
(7.498)\end{array}$ & $\begin{array}{r}0.259 \\
(0.119)\end{array}$ & $\begin{array}{c}4.335 \\
(8.931)\end{array}$ \\
\hline $\begin{array}{l}\text { Requires at least } 10 \%-15 \% \text { return to delay payment to } \\
\qquad 11 \text { years from now }\end{array}$ & $\begin{array}{c}2.699 \\
(5.063)\end{array}$ & $\begin{array}{c}0.184 \\
(0.096)\end{array}$ & $\begin{array}{l}9.249 \\
(7.084)\end{array}$ \\
\hline $\begin{array}{l}\text { Requires at least } 20 \%-25 \% \text { return to delay payment to } \\
\qquad 11 \text { years from now }\end{array}$ & $\begin{array}{l}8.853 \\
(4.901)\end{array}$ & $\begin{array}{c}0.122 \\
(0.099)\end{array}$ & $\begin{array}{l}11.749 \\
(7.185)\end{array}$ \\
\hline $\begin{array}{l}\text { Require higher return for delayed payment } 1 \text { year from } \\
\text { now relative to } 10 \text { years hence }\end{array}$ & $\begin{array}{c}3.967 \\
(4.660)\end{array}$ & $\begin{array}{l}-0.214 \\
(0.102)\end{array}$ & $\begin{array}{c}1.590 \\
(6.498)\end{array}$ \\
\hline Plans to completely stop working after 60 & $\begin{array}{l}1.971 \\
(8.330)\end{array}$ & $\begin{array}{l}-0.286 \\
(0.115)\end{array}$ & $\begin{array}{c}3.700 \\
(8.890)\end{array}$ \\
\hline Likely to change to part-time after 60 & $\begin{array}{l}10.373 \\
(6.334)\end{array}$ & $\begin{array}{l}-0.033 \\
(0.114)\end{array}$ & $\begin{array}{l}14.082 \\
(6.803)\end{array}$ \\
\hline Will work full time for "as long as I can" & $\begin{array}{l}12.511 \\
(7.620)\end{array}$ & (dropped) & (dropped) \\
\hline Expected retirement age is less than or equal to 62 & $\begin{array}{l}-2.820 \\
(6.027)\end{array}$ & $\begin{array}{l}-0.205 \\
(0.100)\end{array}$ & $\begin{array}{l}-5.195 \\
(6.931)\end{array}$ \\
\hline Expected source of benefits is own record & $\begin{array}{c}0.534 \\
(4.251)\end{array}$ & $\begin{array}{c}0.065 \\
(0.087)\end{array}$ & $\begin{array}{l}-1.532 \\
(6.056)\end{array}$ \\
\hline Expected monthly benefits at claiming age & $\begin{array}{c}0.002 \\
(0.003)\end{array}$ & $\begin{array}{c}0.000 \\
(0.000)\end{array}$ & $\begin{array}{c}0.001 \\
(0.004)\end{array}$ \\
\hline Expected change in benefits if delay one year (fraction) & $\begin{array}{c}2.304 \\
(11.824)\end{array}$ & $\begin{array}{c}0.071 \\
(0.233)\end{array}$ & $\begin{array}{c}5.684 \\
(12.681)\end{array}$ \\
\hline Percent chance benefits keep up with inflation & $\begin{array}{c}0.086 \\
(0.075)\end{array}$ & $\begin{array}{l}-0.002 \\
(0.001)\end{array}$ & $\begin{array}{c}0.164 \\
(0.093)\end{array}$ \\
\hline Percent chance benefits cut substantially & $\begin{array}{c}0.135 \\
(0.077)\end{array}$ & $\begin{array}{l}-0.002 \\
(0.001)\end{array}$ & $\begin{array}{c}0.207 \\
(0.098)\end{array}$ \\
\hline Information treatment 2 & $\begin{array}{l}-30.898 \\
(5.735)\end{array}$ & $\begin{array}{c}0.002 \\
(0.106)\end{array}$ & $\begin{array}{l}-29.462 \\
(8.389)\end{array}$ \\
\hline Information treatment 3 & $\begin{array}{l}-8.009 \\
(5.086)\end{array}$ & $\begin{array}{c}0.068 \\
(0.112)\end{array}$ & $\begin{array}{l}-11.219 \\
(7.912)\end{array}$ \\
\hline Information treatment 4 & $\begin{array}{c}-19.804 \\
(5.663)\end{array}$ & $\begin{array}{c}0.072 \\
(0.105)\end{array}$ & $\begin{array}{l}-22.729 \\
(8.039)\end{array}$ \\
\hline constant & $\begin{array}{l}54.726 \\
(14.215)\end{array}$ & $\begin{array}{l}1.205 \\
(0.282)\end{array}$ & $\begin{array}{l}53.056 \\
(17.948)\end{array}$ \\
\hline $\mathrm{R}^{2}$ & 0.236 & 0.241 & 0.250 \\
\hline $\mathrm{N}$ & 289 & $\begin{array}{c}185 \\
\text { (those with } t_{R} *<70 \text { ) }\end{array}$ & $\begin{array}{c}185 \\
\text { (those with } t_{R} *<70 \text { ) }\end{array}$ \\
\hline
\end{tabular}

Standard error estimates are calculated using STATA software (robust regression option) and are reported in parentheses 
Figure 1. Expected Returns to Delayed Claiming

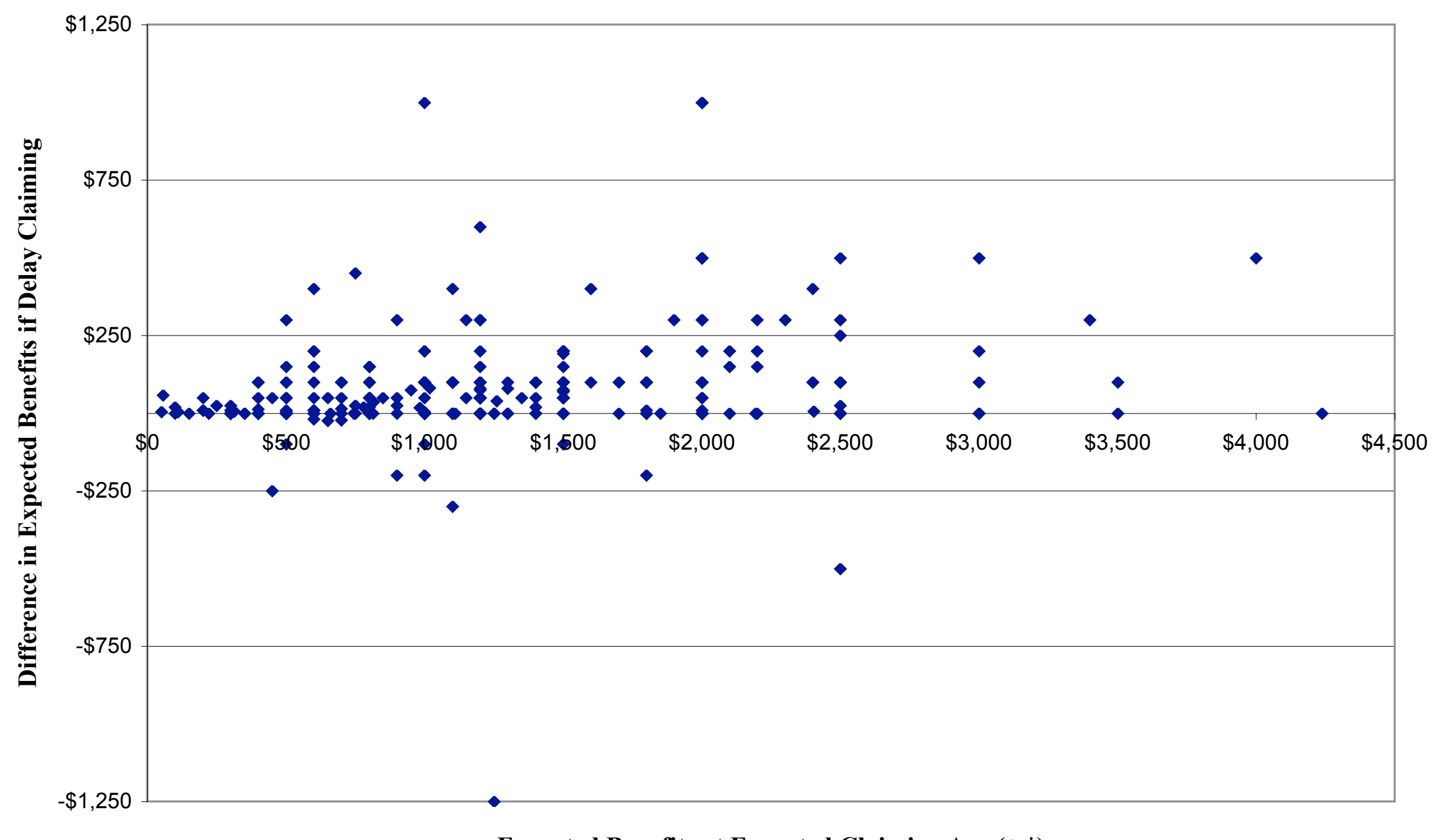

Expected Benefits at Expected Claiming Age $\left(t_{C}{ }^{*}\right)$ 